\title{
Anatomía compararada de óvulos y semillas de dos especies del género Mammillaria (Cactaceae) ${ }^{1}$
}

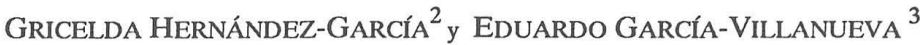

RESUMEN. Se colectaron botones, flores y frutos de Mammillaria rhodantha Link \& Otto y M. compressa De Candolle en diferentes etapas de desarrollo para reconstruir la ontogenia de óvulos y semillas. Se realizaron preparaciones microscópicas por métodos comunes. Los óvulos son campilótropos, crasinucelados y bitégmicos. En M. rhodantha la curvatura nuclear es de $130^{\circ}$ y la micropilar es de $25^{\circ}$. El funículo no tiene tricomas y siempre rodea estrechamente al óvulo. En $M$. compressa la nucela tiene una curvatura de $90^{\circ}$ y el micrópilo una de $\mathrm{O}^{\circ}$. El funículo presenta tricomas en la parte ventral, es largo y a veces no rodea al óvulo; y si lo rodea, no es estrechamente. En $M$. rhodantha el embrión se curva $40^{\circ}$ y en $M$. comress $8^{\circ}$. Los tejidos de reserva son: endospermo y perispermo. La cubierta seminal consta de endotegmen y exotesta.

ABSTRACT. Flowers and fruits in different developmental stages of Mammillaria rhodantha Link \& Otto and $M$. compressa De Candolle were collected to study the ovule and seed ontogeny. Microscopic slides were made by common techinques. The ovules are campylotropous, crassinucellate and bitegmic. The nucellar curvature of M. rhodantha is $130^{\circ}$ and its micropylar curvature is $25^{\circ}$. The funiculus nearly surrounds the ovule and has no trichomes. In $M$. compressa the nucellar curvature is $90^{\circ}$ and its micropylar curvature is $\mathrm{O}^{\circ}$. The funiculus is long and surrounds the ovule incompletely or not at all. Trichomes are present

${ }^{1}$ Este trabajo representa una parte de la tesis de licenciatura presentada en 1988 por la primera autora en la Escuela Nacional de Estudios Profesionales Iztacala, Universidad Nacional Autónoma de México.

${ }^{2}$ Dirección particular: Triunfo No. 92, Col. Campestre Aragón, C.P. 07530, México, D. F.

${ }^{3}$ Centro de Botánica, Colegio de Postgraduados, Chapingo México. Adscripción actual: Academia de Botánica IV, Departamento de Biología, Facultad de Ciencia, Universidad Nacional Autónoma de México, Delegación Coyoacán, 04510, México, D. F.

Hernández-García G, García-Villanueva E. 1991. Anatomía compararada de óvulos y semillas de dos especies del género Mammillaria (Cactaceae). Boletín de la Sociedad Botánica de México 51: 25-38. 
on the ventral side. The embryo is curved in both species, $40^{\circ}$ in $M$. rhodantha and $8^{\circ}$ in $M$. compressa. The food reserve tissues are: perisperm and endosperm. The seed coat is formed from endotegmen and exotesta.

Las mamilarias son plantas muy apreciadas como ornamentales, porque son fáciles de cultivar y presentan flores muy atractivas. México es el centro de distribución del género Mammillaria, y hospeda más de cincuenta por ciento de las trescientas cincuenta especies descritas (Scheinvar, 1982). A pesar de ésto, los estudios acerca del mismo son escasos en nuestro país. Como en otros integrantes de la familia Cactaceae, es necesario realizar investigaciones biológicas para ayudar a resolver problemas taxonómicos. La clasificación actual del género considera características de las semillas, espinas, flores y tipo de savia (acuosa, semilechosa y lechosa).

En los óvulos y las semillas de Cactaceae, las características anatómicas de interés taxonómico son: la forma y posición del funículo, la ausencia o presencia de endospermo o perispermo; las ornamentaciones de la cubierta seminal y las curvaturas: micropilar, de la nucela y del embrión (Flores, 1976; Barthlott y Voit, 1979). Existe una relación directa entre la curvatura nucelar y la del embrión, y una inversa entre aquella y la del micrópilo. Mientras menor sea la relación: largo del embrión entre largo de los cotiledones, mayor es la curvatura del embrión (Flores, 1976).

En la subfamilia Pereskioideae el funículo es corto; en algunas Cereoideae rodea al óvulo y en Opuntioideae cubre toda la semilla. Dentro del género Mammillaria la cubierta seminal tiene especial importancia. En el subgénero Mammilloydia las semillas son negras sin fóveas intercelulares, los subgéneros Dolichothele, Cochemiea, Mammillopsis y Mammillaria presentan semillas pardas o negras (Hunt, 1979).

Los objetivos del presente trabajo fueron: describir la anatomía de la semilla madura de dos especies de Mammillaria y conocer la ontogenia de sus partes, además, detectar diferencias anatómicas entre ambas y sugerir su posible importancia taxonómica.

\section{MATERIALES Y MÉTODOS}

Se trabajó con dos especies del género Mammillaria subgénero Mammillaria (figs. 1 y 2): $M$. rhodantha Link \& Otto (Sección Subhydrochylus serie Heterochlorae) y $M$. compressa De Candolle (sección Mammillaria serie Macrothelae). Ejemplares depositados en el Herbario Nacional de México (MEXU). Colectados y determinados por Gricelda Hernández García y Ulises Guzmán (M. rhodantha en 1986 y M. compressa en 1987).

Se obtuvieron botones, flores en antesis, y frutos en diferentes etapas de desarrollo como sigue: M. rhodantha en La Purificación, Texcoco, Estado de México y M. compressa en Colón, Querétaro (cabecera municipal). Se trasplantaron varios ejemplares a la Ciudad de México y se marcaron diferentes estados fenológicos de floración para 
cuantificar el tiempo que tardaron en pasar a una etapa posterior. Se correlacionó la edad de los botones florales con la longitud de los segmentos del perianto y con la anatomía de los óvulos.

Se marcaron únicamente los frutos obtenidos de flores polinizadas manualmente. Fue difícil distinguir frutos en etapas intermedias de desarrollo ya que no se observaron diferencias en su apariencia externa. Además, permanecen ocultos entre los tubérculos hasta que maduran totalmente.

Después se fijó el material en Craf III (Berlyn y Miksche, 1976) y se siguió la técnica normal para obtener preparaciones permanentes de cortes de parafina (Jensen, 1962). Los ovarios se cortaron transversalmente, lo que permitió observar óvulos en plano mediano (fig. 6). Las semillas se separaron del fruto para orientarlas individualmente en plano mediano. Se tiñó principalmente con safranina y verde fijo. Ocasionalmente se usó lugol para almidón, ácido peryódico-reactivo de Schiff (APS) para polisacáridos y negro de sudán o rojo 0 de aceite para lípidos. El grosor de los cortes fue de diez micrómetros.

En esquemas del plano mediano se midieron: las curvaturas nucelar (fig. 3), micropilar (fig. 4) y del embrión (fig. 5).

\section{RESUlTADOS}

A) Ovulos. 1. Saco embrionario y nucela. El saco embrionario es octanucelado y heptacelular, se origina de la megaspora calazal (fig. 8) y su desarrollo es tipo Polygonum (Maheshwari, 1950). El megagametofito se encuentra maduro cinco días antes de antesis (fig. 17). Las flores permanecen abiertas dos días para ser polinizadas. Cuando la fecundación ocurre, las antípodas desaparecen, los núcleos polares se fusionan y las sinérgidas se empiezan a desintegrar. La ovocélula presenta unas partículas adheridas a la pared celular que se tiñen con safranina; la célula central presenta almidón (fig. 9). En la antesis el extremo micropilar de la nucela presenta varios estratos celulares (óvulo crasinucelado). Em ambas especies la nucela se curva en diferente grado (tabla 1), por lo tanto, se trata de óvulos campilótropos. Además el valor de dicha curvatura va aumentando conforme el óvulo se transforma en semilla hasta un máximo aproximadamente catorce semanas después de antesis (tabla 1 y figs. 10, 11 y 17).

2. Tegumentos y micrópilo. Dos tegumentos cubren la nucela (fig. 17). Ambos tienen dos estratos celulares excepto en la zona micropilar donde se pluristratifican (figs. 10 y 11). El lumen y la pared de la epidermis interna del tegumento interno se tiñen ligeramente con safranina en el extremo micropilar. Las células del tegumento externo son las más grandes del óvulo (figs. 10 y 11), el corte tangencial son irregularmente lobuladas.

La longitud del tegumento externo ventral libre (fig. 17 parte sombreada letra Y) entre el largo máximo del óvulo es de 0.00 en $M$. rhodantha y de 0.10 en $M$. compressa. 
TABLA 1. Características de los óvulos y las semillas que difieren entre $M$. rhodantha y M. compressa.

\section{M. rhodantha M. compressa}

1. Ovulo en antesis
a) Curvatura micropilar.
$25^{\circ}$
$0^{\circ}$
b) Tegumento externo ventral libre entre largo máximo del óvulo
0.00
0.10
c) Largo micropilar entre largo máximo del óvulo.
0.15
0.25
d) Funícullo rodea al óvulo.
Siempre
A veces no
e) Protuberancia en la rafe.
$\mathrm{Si}$
No
f) Funículo con tricomas ventrales.
No
g) Curvatura nucelar.
$130^{\circ}$
$\mathrm{Si}$
h) Curvatura nucelar máxima (en semilla inmadura).
$140^{\circ}$ $90^{\circ}$
$125^{\circ}$

2. Semilla madura.
a) Curvatura del embrión.
b) Forma general.
c) Pared externa de las células testales.

$40^{\circ}$

$8^{\circ}$

Ovoide

Menos gruesa

Más gruesa

El micrópilo es la vía de entrada del tubo polínico, y está formado sólo por el tegumento interno (figs. 8, 10 y 11). El largo micropilar entre el largo máximo del óvulo es de 0.15 en $M$. rhodantha y de 0.25 en $M$. compressa. Esto quiere decir que el micrópilo de $M$. compressa es relativamente más grande que el de M. rhodantha.

3. Rafe. La rafe es muy grande y no se curva, a diferencia de otros óvulos campilótropos (figs. 10, 11 y 17).

4. Funículo e hilo. El funículo es un cordón que une al óvulo con la placenta del ovario, y contiene el haz vascular (fig. 7). Es muy largo y se puede curvar para rodear parcialmente al óvulo (figs. 11 y 17). Por extrapolación de observaciones en semillas se puede señalar en el óvulo la posición del hilo próxima al micrópilo (fig. 17). 
B. Semilla. 1. Embrión. Cinco días después de antesis el cigoto aún no se divide y el endospermo ya presenta varios núcleos libres. El embrión alcanza su tamaño máximo y es recto antes de que el perispermo (nucela persistente) acumule almidón (fig. 12). Posteriormente, el eje de los cotiledones se curva con respecto al eje del extremo radicular (fig. 18). El embrión maduro tiene forma globular. Los cotiledones son dos pequeñas protuberancias en medio de los cuales se encuentra el meristemo apical del vástago (figs. 13 y 18). No hay plúmula. El hipocótilo constituye la mayor parte del volumen de la semilla y la radícula se encuentra hacia el extremo micropilar (figs. 13 y 18).

Las células parenquimáticas del embrión contienen gránulos que probablemente son de naturaleza proteica dada su estructura cristalina y su afinidad por el verde rápido en extracción anhidra (figs. 14 y 15). El procámbium se encuentra en el centro de la radícula y se abre alrededor de una médula en el hipocótilo (figs. 13 y 18).

2. Tejidos de reserva. En la semilla, el principal es el hipocótilo. Los tejidos de reserva extraembrionarios son perispermo y endospermo (figs. 12 y 13). El tipo de desarrollo del endospermo es nuclear. En la semilla madura se retiene alrededor de la radícula y parte del hipocótilo. Está formado por un estrato de células que tienen gránulos supuestamente proteicos que se tiñen con safranina y paredes gruesas que tienen afinidad por el APS (figs. 12, 13 y 19). El perispermo deriva de la nucela y de la cálaza. Se localiza en la región calazal entre el embrión, el endotegmen y la rafe. almacena almidón (figs. 13 y 18).

3. Cubierta seminal. a) Tegmen. El exotegmen desaparece a las tres semanas de desarrollo de las semillas. Al mismo tiempo, las células del endotegmen se alargan ligeramente y alcanzan su tamaño definitivo. En la zona micropilar, éstas se empiezan a llenar de una sustancia que aparece rojiza y difusa (probablemente taninos que por su oxidación durante la técnica histológica toman dicho color), en el resto de la semilla quedan vacías (fig. 19 ta). Las células de la parte externa del micrópilo se aplastan. La pared de las células del endotegmen se tiñe con APS y safranina, en las paredes periclinales internas se observan unas estrías pequeñas (fig. 19). En ambos lados del endotegmen se observan las cutículas: tegmen-nucelar e intertegumentaria. Estas tiñen con negro sudán y rojo 0 de aceite (figs. 14 y 15).

b) Testa. La endotesta se mantiene durante las primeras etapas de desarrollo, y desaparece cuando el embrión cesa su crecimiento. En la zona micropilar la testa presenta tres estratos celulares. En el resto de la semilla perdura sólo la exotesta cuyas células tienen su mayor crecimiento durante las tres primeras semanas posteriores a la antesis. Después se deposita la pared secundaria y las vacuolas se llenan de sustancias que aparecen fuertemente rojizas (probablemente taninos). En corte tangencial, las células de la exotesta son irregularmente lobuladas y encajan entre sí como piezas de un rompecabezas (fig. 16). Esto origina una ornamentación particular (similar en ambas especies). En la vista anticlinal que da un corte mediano, dichas prolongaciones aparentan ser células pequeñas intercaladas con células grandes. Las paredes anticlinales son 
refringentes y muy delgadas. la pared periclinal externa engrosada tiñe con APS, sin tinción es transparente y homogénea (figs. 14, 15 y 19). Esta pared se adelgaza en los límites anticlinales entre dos células (fig. 16). Las células de la exotesta están alargadas en el sentido micrópilo-calazal excepto en esos extremos donde son isodiamétricas. Finalmente, quedan llenas de sustancias que probablemente dan el color pardo claro a la semilla. En la superficie externa de la exotesta se observa una cutícula muy delgada (figs. 14, 15 y 19).

4. Cálaza, rafe e hilo. El tejido vascular de la rafe entra un poco en la cálza. El parénquima interno de la cálaza forma perispermo. La mayor parte del parénquima de la rafe presenta paredes muy delgadas y citoplasma hialino (fig. 12). El hilo es la zona de abscisión de la semilla y se encuentra a un lado de la radícula en la cubierta seminal. El micrópilo se oblitera. La zona hilo-micropilar es elíptica y presenta células que se tiñen con safranina (figs. 12 y 18). Las diferencias anatómicas encontradas entre las dos especies aparecen en la tabla 1.

\section{DisCUSIÓN}

Los óvulos son semejantes a los de otros miembros de la familia: campilótropos, crasinucelados y bitégmicos. El desarrollo del saco embrionario es del tipo Polygonum como en la mayoría de las angiospermas. En el micrópilo el tegumento externo se queda un poco atrás con respecto al tegumento interno, ésta es una característica que Neumann (1935); Bhojwani y Bhatnagar (1978) señalan para Cactaceae y otras familias de Centrospermae.

La relación: tegumento externo ventral libre entre largo máximo del óvulo, está relacionada con el funículo; si éste rodea estrachamente al óvulo, la relación anterior es 0.00 (M. rhodantha), y si no lo rodea estrechamente la relación es 0.10 (M. compressa).

Los resultados obtenidos acerca de la longitud y la curvatura del micrópilo no coinciden con lo que menciona Flores (1976). El micrópilo de $M$. compressa es más grande y menos curvo que el de M. rhodantha. Según Flores (1976), el micrópilo más largo es el que tiene mayor curvatura. Coincidimos con Engleman (1960); Corner (1976) y Flores y Engleman (1976) en que hay perispermo y endospermo.

A diferencia de lo señalado por Tiagi (1956 y 1957) en Mammillaria tenuis, las especies estudiadas no presentan poliembrionía. La mayor parte del embrión es hipocótilo y los cotiledones no son foliares. El embrión de las especies estudiadas es semejante a los descritos por Flores y Engleman (1976) en integrantes de la subfamilia Cereoideas. La curvatura del embrión da la forma a las semillas que va de ovoide $\left(8^{\circ}\right)$ a piriforme $\left(40^{\circ}\right)$. El embrión casi recto de $M$. compressa es más avanzado que el embrión curvo de M. rhodantha; de acuerdo con lo que plantea Flores (1976) y con las relaciones filogénicas que según Hunt (1979) existen entre estas dos especies. 
No se encontraron diferencias en las células testales de ambas especies, ésto coincide con Hunt (1979) en que la cubierta seminal de las secciones Mammillaria y Subhydochylus es muy semejante. Las estrías en las paredes del endotegmen son una característica de Centrospermae según Netolitzky (1926) y Flores y Engleman (1976).

Las diferencias anatómicas encontradas entre las dos especies tienen importancia taxonómica porque uxilian en su caracterización. Se sugiere continuar con estudios de este tipo ya que al obtener datos cuantitativos se tiene la posibilidad de ayudar a resolver problemas taxonómicos.

\section{TEXTO DE FIGURAS}

Fig. 1. Mamillaria rhodantha la planta adulta no es ramificada.Vista apical. 0.7X.

Fig. 2. Mammillaria compressa, planta adulta cespitosa vista apical de una rama. $0.7 \mathrm{X}$.

Fig. 3. Forma de medir la curvatura nucelar, modificada de Flores (1976). Se traza una línea en el eje principal de la nucela -su región más larga- (AA'). Se traza otra línea en el plano de la base de la nucela (BB'). Se traza una línea perpendicular a BB' en el eje de la base de la nucela (CC'). Se mide el ángulo $\propto$

Fig. 4. Forma de medir la curvatura micropilar, modificada de Flores (1976). Se traza la línea (AA') igual que en la fig. 3. Se traza otra línea en el eje principal del micrópilo (DD'). Se mide el ángulo $\beta$

Fig. 5. Forma de medir la curvatura del embrión, modificada de Flores (1976). Se traza una línea en el eje del extremo radicular del embrión (GG'). Se traza otra línea en el eje entre los extremos de los cotiledones (FF'). Se traza la línea EE' paralela a FF' que corte GG'. Se mide el ángulo r entre las líneas EE' y GG'. Si la línea FF' corta a GG', ૪ está entre ellas y es menor de $90^{\circ}$.

Fig. 6. Corte transversal de ovario de $M$. compressa con 7 placentas parietales, $70 \mathrm{X}$.

Fig. 7. Ovulo de $M$. compressa en plano mediano 3 semanas antes de antesis, $420 \mathrm{X}$.

Fig. 8. Ovulo de $M$. compressa en plano mediano, 2 semanas antes de antesis, $610 \mathrm{X}$.

Fig. 9. Aparato ovocelular de $M$. compressa en antesis, plano mediano, 1080X.

Fig. 10. Ovulo de $M$. rhodantha en antesis, plano mediano, 230X.

Fig. 11. Ovulo de M. compressa 7 días antes de antesis, plano casi mediano, 260X.

Fig. 12. Semilla casi madura ( 5 meses después de antesis) de M. rhodantha en plano mediano. La nucela persistente $(\mathrm{N})$ se transformará en parte del perispermo, $80 \mathrm{X}$.

Fig. 13. Semilla madura de $M$. compressa en plano casi mediano, $90 \mathrm{X}$.

Fig. 14. Cubierta seminal madura de M. rhodantha. Sección anticlinal, 500X.

Fig. 15. Cubierta seminal madura de $M$. compressa. Sección anticlinal, 510X.

Fig. 16. Cubierta seminal madura de $M$. compressa, corte tangencial en la antirrafe, $270 \mathrm{X}$.

Fig. 17. Esquema de los óvulos 5 días antes de antesis. A) M. rhodantha; B) M. compressa, A y B 140X.

Fig. 18. Esquemas de las semillas maduras. A) M. rhodantha, 50X; B) M. compressa, 40X.

Fig. 19. Esquema de la cubierta seminal (seccion anticlinal) en la antirrafe (ver fig. 18), 200X. Acotaciones: $\mathrm{AL}=$ gránulos de almidón de la célula central; $\mathrm{CO}=$ cotiledones; $\mathrm{CS}=$ cubierta seminal (en la antirrafe); DMm = célula madre de la megaspora en la primera división meiótica; $\mathrm{ED}=$ endospermo; $\mathrm{EM}=$ embrión; $\mathrm{EN}=$ emdotegmen; $\mathrm{ET}=$ exotesta; $\mathrm{F}=$ funículo; $\mathrm{G}=$ gránulo; $\mathrm{H}=$ hipocótilo; $\mathrm{Hi}=$ hilo o región del hilo; $\mathrm{L}=$ cálaza; $\mathrm{La}=$ cutícula externa; $\mathrm{Lb}=$ cutícula intertegumentaria; $\mathrm{Lc}=$ cutícula tegmen- 
nucelar; lu = lumen celular de la exotesta; $\mathrm{M}=$ micrópilo; $\mathrm{Ma}=$ Meristemo apical del vástago; $\mathrm{Mm}$ = célula madre de la megaspora; $\mathrm{N}=$ nucela; $\mathrm{Nu}=$ núcleo de la ovocélula; $\mathrm{Ov}$ = ovocélula (entre las flechas); $\mathrm{P}=$ Perispermo; $\mathrm{Pf}=$ protuberancia en la rafe; $\mathrm{Pm}=$ procámbium; $\mathrm{Pp}=$ pared primaria del endospermo; $\mathrm{Pr}=$ pared periclinal externa. $\mathrm{RA}=$ rafe; $\mathrm{Rd}=$ radícula; $\mathrm{r}=$ estrías; $\mathrm{S}=$ sinérgidas algo destruidas; $\mathrm{SE}=$ saco embrionario; $\mathrm{ta}=$ cuerpos subcelulares rojizos; $\mathrm{TI}=$ tegumento interno; $\mathrm{tr}=$ tricoma; $\mathrm{TX}=$ tegumento externo; $\mathrm{Vx}=$ tejido vascular en la rafe; $\mathrm{Y}=$ tegumento externo ventral.
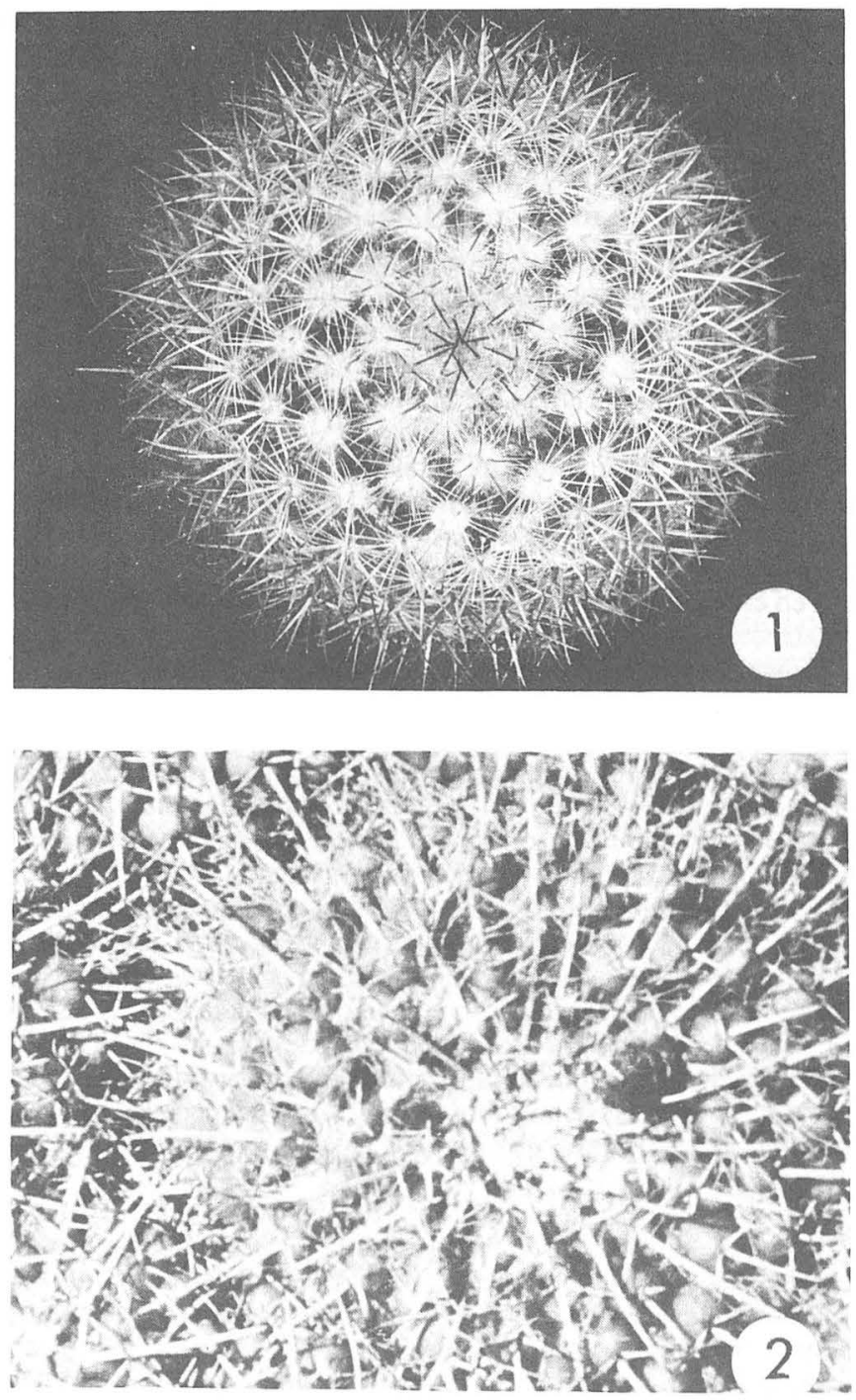

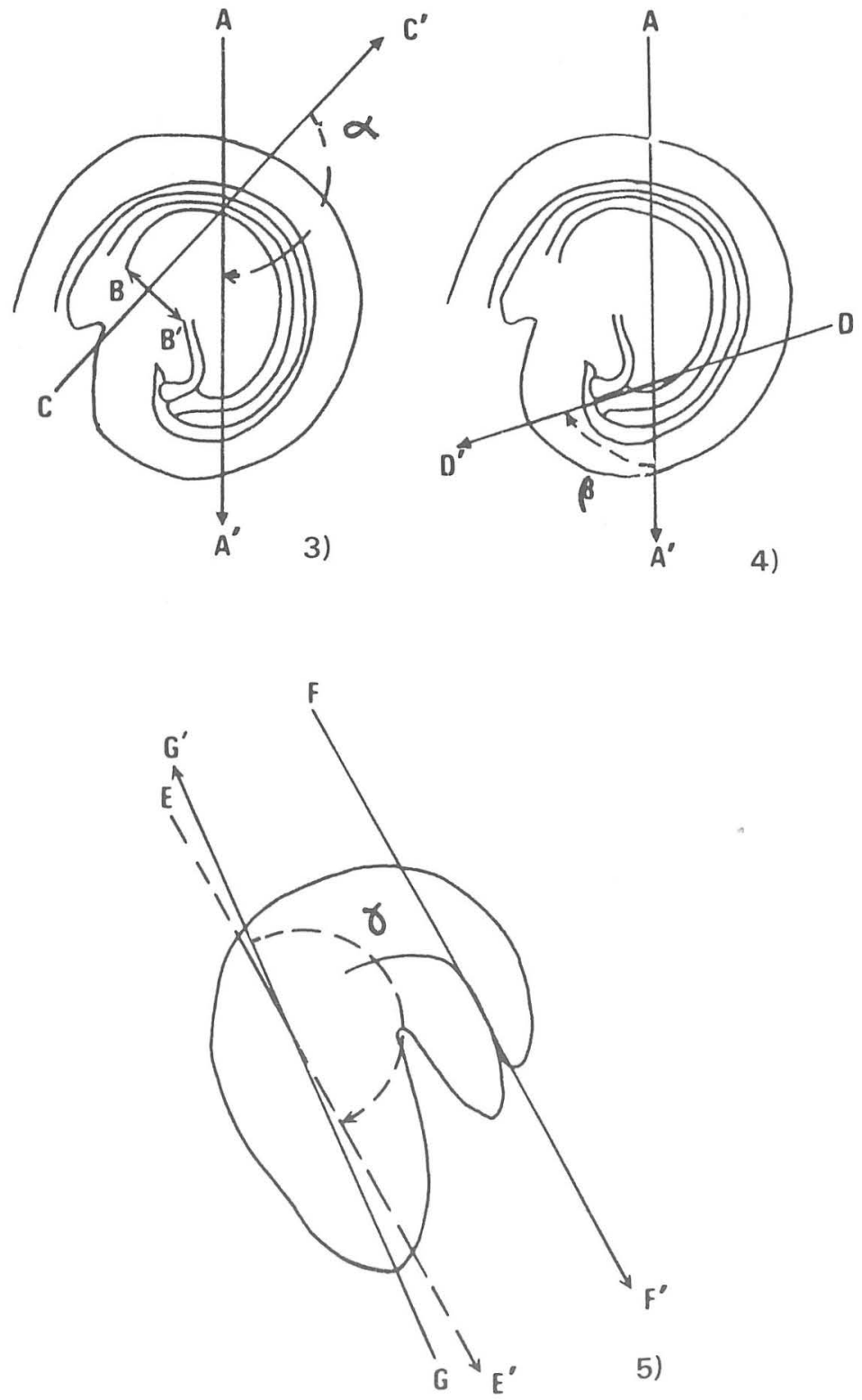


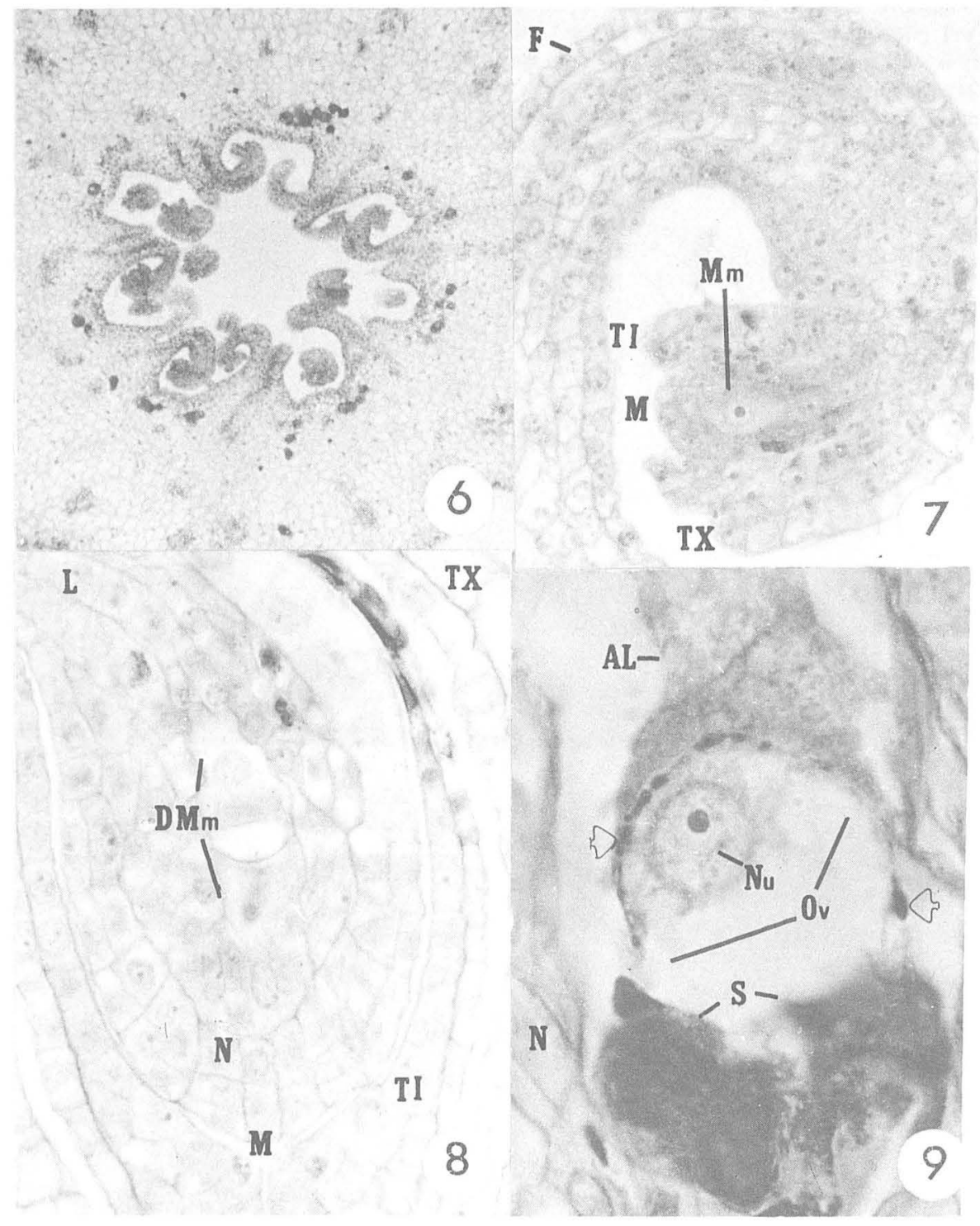




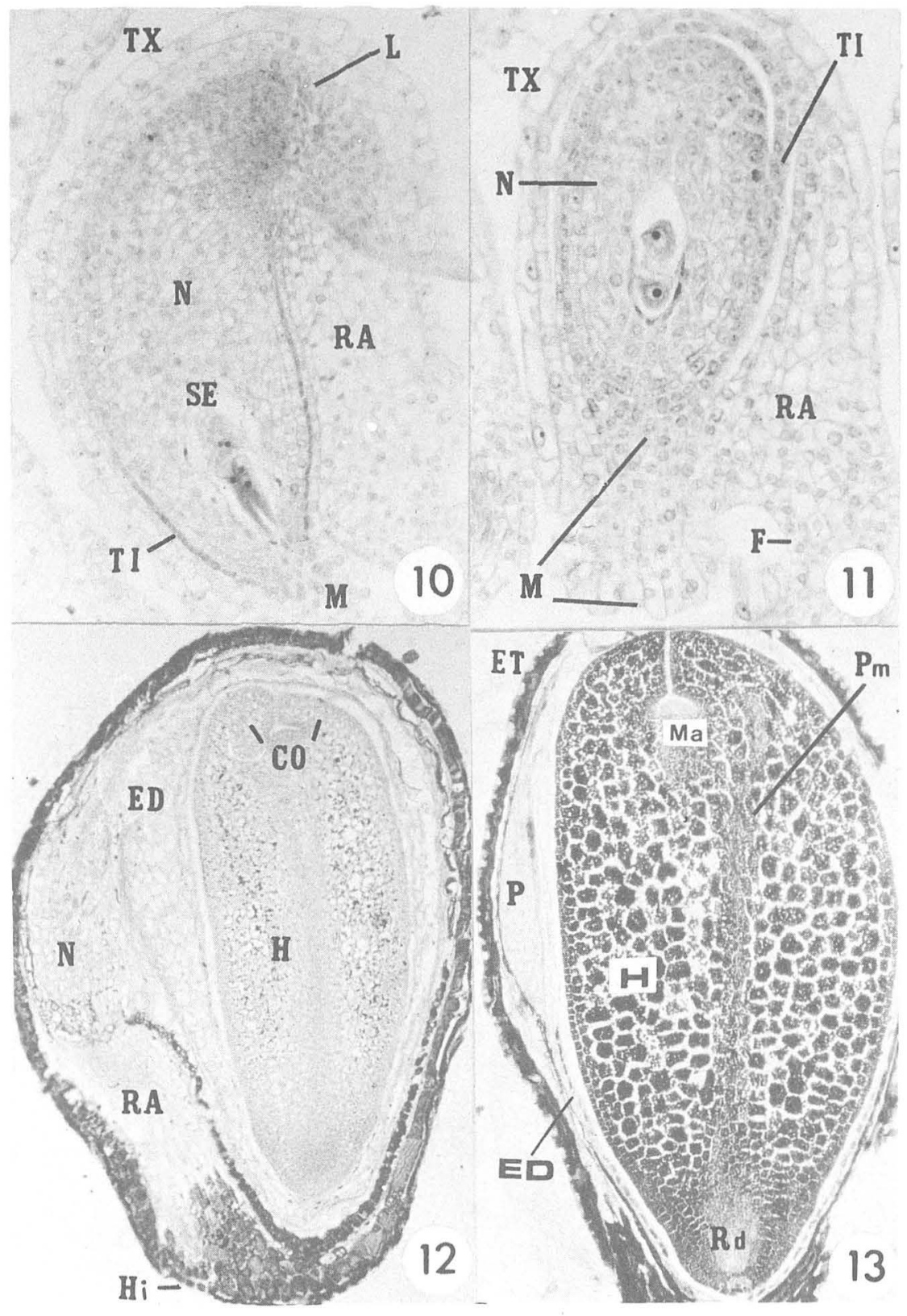




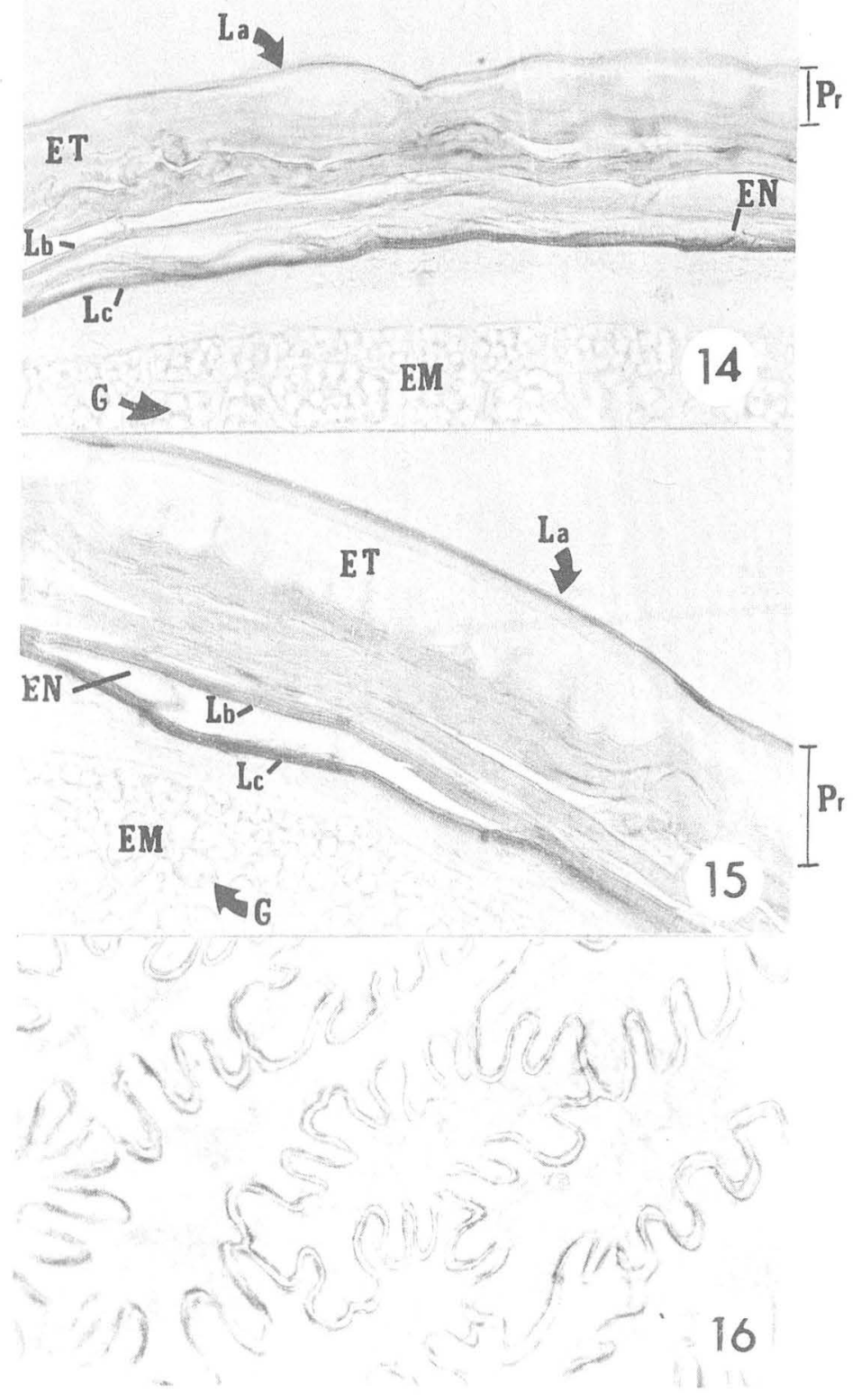




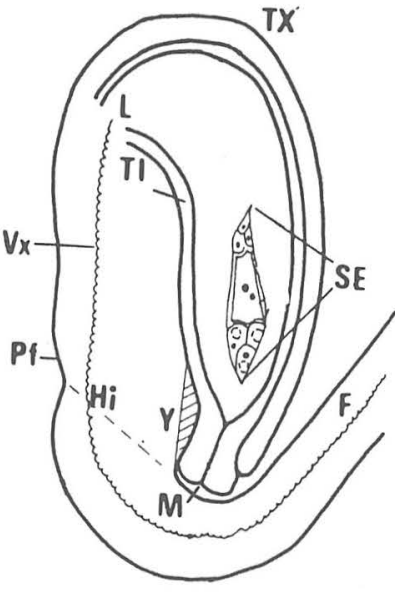

A

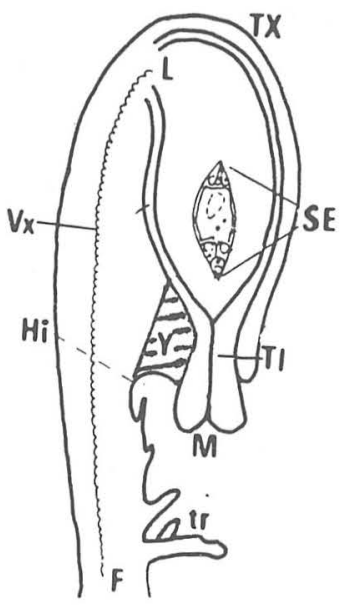

B

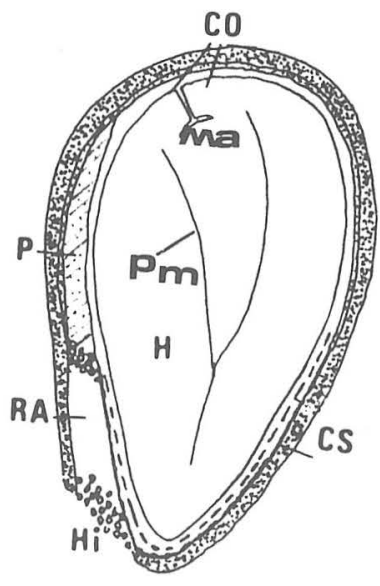

A

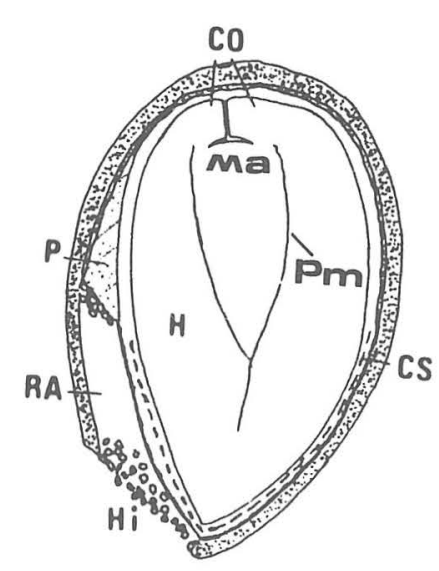

18)

B 


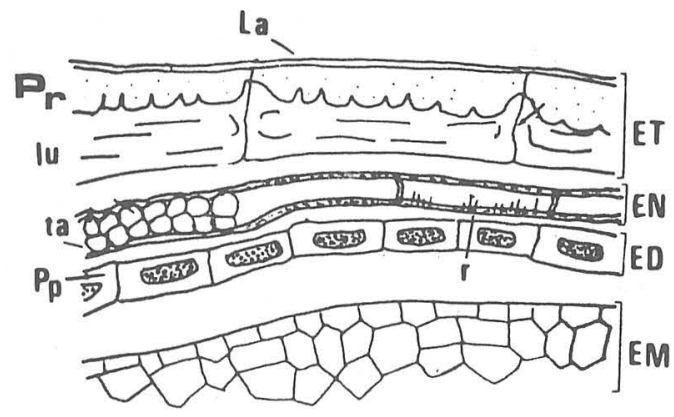

19

Agradecimientos. Al Dr. E. M. Engleman del Centro de Botánica del Colegio de Postgraduados (Chapingo, México) por facilitarnos el uso del laboratorio de Anatomía, la computadora donde se realizó este escrito y su biblioteca particular. Le agradecemos también su apoyo constante durante el desarrollo de este trabajo y sus sugerencias para mejorar el escrito final. Al Pas. de Biól. L. Ulises Guzmán por la ayuda en la identificación de las especies y por el material bibliográfico prestado.

\section{LITERATURA CITADA}

BARTHOLOTT, W. y G. VOIT. 1979. Micromorphologie der samenschalen und taxonomie der Cactaceae: Ein raster-elektronenmikroskopischer Überblick. Plant Syst. Evol. 132: 205-229.

BERLYN, G. P. y J. P. MIKSCHE. 1976. Botanical microtechnique and cytochemistry. Iowa State University Press, Ames. 326p.

BhojWAnI, S. S. y S. P. BhatnagaR. 1978. The embryology of angiosperms. 3a. ed. Vikas Publishing House, New Delhi. 280p.

CORNER, E. J. H. 1976. The seeds of dicotyledons. Cambridge University Press, London. 2 v.

ENGLEMAN, E. M. 1960. Ovule and seed morphology of certain cacti. Amer. J. Bot. 47: 460-467.

FLORES, E. M. 1976. Apuntes sobre anatomía y morfología de las semillas de cactáceas. II. Caracteres de valor taxonómico. Rev. Biol. Trop. 24 (2): 299-321.

Flores, E. M. y E. M. ENGLEMAN. 1976. Apuntes sobre anatomía y morfología de las semillas de cactáceas. I. Desarrollo y estructura. Rev. Biol. Trop. 24 (2): 199-227.

JENSEN, W. A. 1962. Botanical histochemistry. Principles and practice. Freeman, San Francisco, 408p.

HuNT, D. R. 1979. Recent Mammillaria discoveries. Cact. Succ. J. Great Britain 45(4):95-110.

MAIIESHWARI, P. 1950. An introduction to the embryology of angiosperms. McGraw Hill, New York. $453 p$.

NETOLITZKY, F. 1926. Anatomie der angiospermen-Samen. Handbuch der Pflanzenanatomie. Borntraeger, Berlin. 364p.

NEUMANN, M. 1935. Die Entwicklung des Pollens, der Samenanlage und des Embryosackes von Pereskia amapola var. argentina. Öster. Bot. Zeitschr. 84:1-30.

SCHEINVAR, L. 1982. La familia de las Cactáceas en el Valle de México. Tesis Doctoral. Facultad de Ciencias, UNAM, México. 726p.

TIAGI, Y. D. 1956. Polyembryony in Mammillaria tenuis D. C. Bull. Bot. Soc. Univ. Sougar 8:25-27.

TIAGI, Y. D. 1957. Studies in floral morphology. III A contribution to the floral morphology of Mammillaria tenuis D.C. J. Univ. Sougar 6(part II sect. B):7-13. 